\title{
Thoracic Incidentaloma in a 55-year-old Woman Discovered on CT Scan at the "Luxembourg" Mother Child Hospital Center Mariko $\mathrm{M}^{1}$, Camara $\mathrm{M}^{1^{*}}$, Sanogo $\mathrm{S}^{1}$, Kouma $\mathrm{A}^{1}$, Konaté $\mathrm{M}^{2}$, Camara $\mathrm{T}^{3}$
}

\author{
${ }^{1}$ Medical Imaging Department, Mother-Child University Hospital "Luxembourg", Mali \\ ${ }^{2}$ Medical Imaging Department, CHU Point G, Bamako, Mali \\ ${ }^{3}$ Department of Internal Medicine of the prefectural hospital of Siguiri / Guinea
}

DOI: $10.36347 /$ sasjm.2022.v08i01.001

| Received: 19.11.2021 | Accepted: 22.12.2021 | Published: 07.01.2022

*Corresponding author: Dr. Camara M

Abstract

The aim of this work was to clarify the CT aspects of an asymptomatic Morgagni hernia discovered incidentally on a Thoraco-Abdomino-Pelvic scanner. Patient: We report the case of a 55-year-old woman who came for assessment of the extension of a tumor of the rectum in whom a thoraco-abdomino-pelvic scan was performed which fortuitously revealed the right Morgagni hernia. No treatment was offered. Radiographic control of Morgagni's hernia after 6 months of the CT scan showed lesional stability. Conclusion: Morgagni's hernia is a rare entity, most often discovered by accident. However, this hernia is often asymptomatic and does not require treatment. The positive diagnosis is fortuitously evoked on a CT scan after another assessment and monitoring can be done on a standard radiography in order to limit the X-ray irradiation.

Keywords: Morgagni hernia, incidentaloma, CT, thorax.

Copyright (C) 2022 The Author(s): This is an open-access article distributed under the terms of the Creative Commons Attribution 4.0 International License (CC BY-NC 4.0) which permits unrestricted use, distribution, and reproduction in any medium for non-commercial use provided the original author and source are credited.

\section{INTRODUCTION}

Morgagni-Larrey diaphragmatic hernia is a rare condition, which accounts for $3 \%$ of all diaphragmatic hernias [1].

Its location is always anterior, at the expense of the two diaphragmatic areas of weakness that are the Morgagni (right) and Larrey (left) foramina. When the hernia is symptomatic, the signs reported are most often of a respiratory nature, but also digestive (heartburn, vomiting, occlusive syndrome) or cardiac (atypical chest pain, tamponade) [1].

Morgagni's diaphragmatic hernia is a malformation of neonatal disclosure, however the latency period is sometimes long until adulthood, the clinical manifestations are not specific and diagnostic errors are numerous, thus delaying their management.

The diagnostic suspicion goes through the standard thoraco-abdominal radiography. The diagnostic confirmation is scannographic objectifying an ascension of the abdominal organs in intrathoracic through an anterior diaphragmatic defect [2]. Magnetic resonance imaging (MRI) can be useful when in doubt to identify the defect in the diaphragmatic wall [2]. The treatment of retro-costo-xiphoid hernia is surgical [3].

These pathologies can go unnoticed either because of the ignorance of certain radiologists or if they are asymptomatic.

We report a case of Morgagni's hernia discovered incidentally after a thoraco-abdominal CT scan for assessment of the extension of a lieberkuhnian tumor of the rectum.

The objective of this work was to clarify the CT aspects of an asymptomatic Morgagni hernia discovered incidentally on a thoraco-abdominal-pelvic scan.

\section{OBSERVATION}

We report the case of a 55-year-old patient with a history of rectal tumor operated on without a history of thoraco-abdominal trauma or pneumonia, received in our department in her 3rd thoracoabdominal-pelvic CT imaging session for assessment of extension. 
On clinical examination, the patient was in good general condition, afebrile. Cardiovascular and pulmonary auscultation were without abnormalities. On palpation and percussion no peculiarity was noted.

Fortuitously, the thoraco-abdominal CT scan with injection was able to highlight a large diaphragmatic hernia $115 \times 61 \mathrm{~mm}$ through a right retrocosto-diaphragmatic dehiscence with omental and fatty content, the neck of which measured $24 \mathrm{~mm}$ in diameter. Absence of abnormalities of the cardiac structures.

Note that the herniated structures were not enhanced after contrast injection. The rest of the exam was normal. The biological assessment was normal.
The patient being asymptomatic did not receive any treatment apart from her chemotherapy courses.

The standard AP chest x-ray taken after 6 months of the CT scan showed the stability of the hernia.

Our greatest concern was that this diagnosis was missing from previous accounts, and the condition did not appear to be recent.

\section{ICONORAPHS}

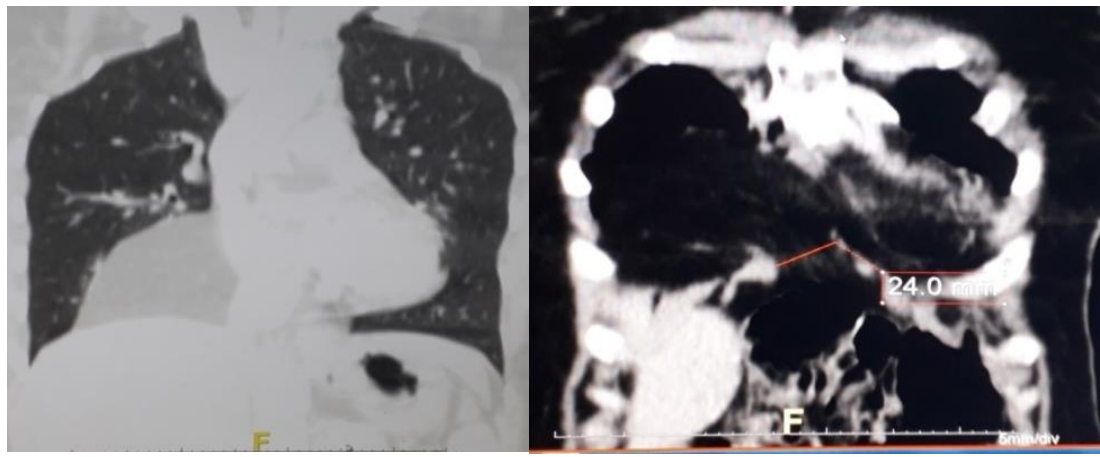

Figure 1: TAP CT in mediatisnal and parenchymal windows and in coronal reconstruction showing a large right diaphragmatic hernia through a right retro-costo-diaphragmatic dehiscence whose neck measures $24 \mathrm{~mm}$ in diameter

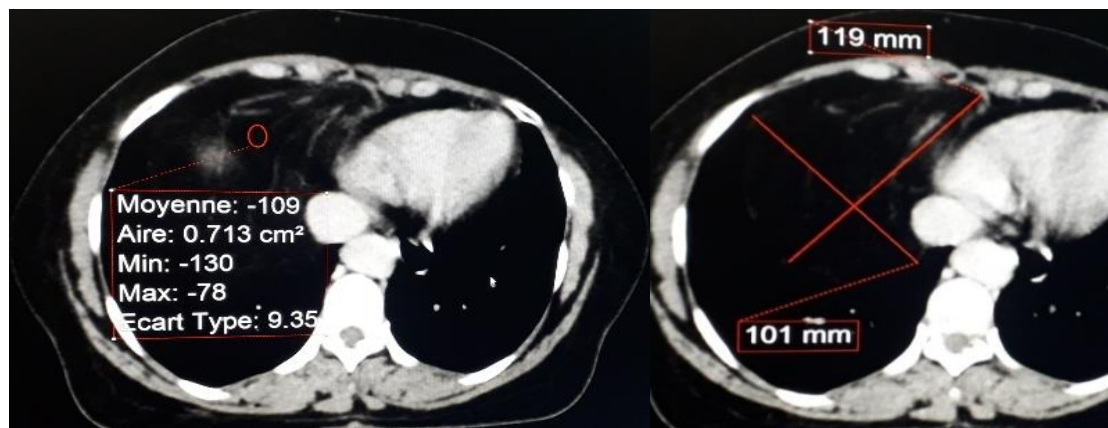

Figure 2: Thoracic CT in axial section and in mediastinal window with injection of contrast product showing a large diaphragmatic hernia $115 \times 61 \mathrm{~mm}$ through a right retro-costo-diaphragmatic dehiscence with omental and fatty contents

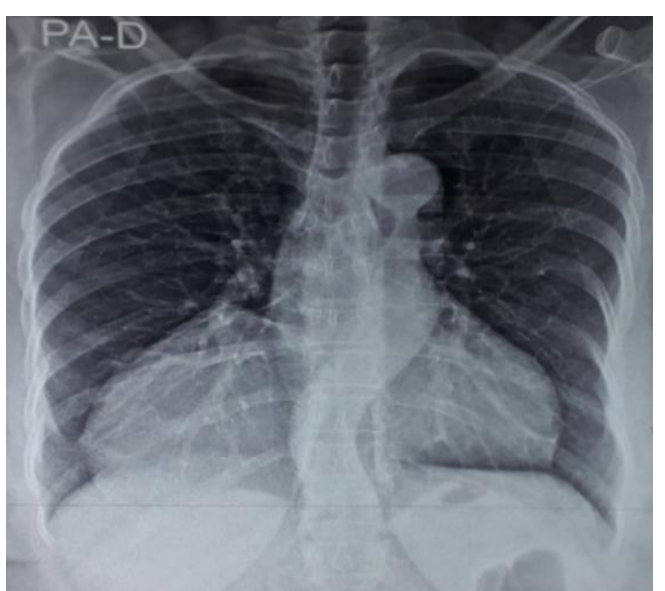

Figure 3: Frontal chest radiographic check showing the right Morgagni hernia after 6 months of the 3rd thoraco-abdominopelvic scan

\section{DISCUSSION}

Morgagni's hernias (or retro-costo-xiphoidal or anterior), described by Morgagni in 1761, constitute the rarest form of diaphragmatic hernias and represent 5 to $10 \%$ of congenital diaphragmatic hernias [4] and $2.5 \%$ of the all diaphragmatic hernias treated surgically [5]. They sit at the junction of the diaphragm and the anterior part of the trunk [6]. This matches the topography of our lesion.

They develop in 70 to $90 \%$ of cases on the right $[2,7]$ and in $2 \%$ of cases on the left due to the presence of the cardiac mass, they are bilateral in $7 \%$ of cases [2]. In our case, it sat on the right. The average age of diagnosis is 50 years [8]. Our patient was 55 years old when the lesion was discovered. The largest series of Morgagni's hernias published by John D 
Horton et al concerns clinical data from 298 patients collected from 135 articles [9]. In this study women accounted for $62 \%$ of cases, the overall mean age of discovery was 53 years, with age ranges of 56-60 years for women, 31-70 years for men. Our case was a 55year-old patient at the time of diagnosis The diagnosis of a hernia.

Morgagni or Larrey is evoked on the chest Xray which shows an anterior and inferior mediastinal opacity, of variable density according to the content of the hernial organs. The confirmation is scannographic objectifying an ascension of the abdominal organs in intrathoracic through an anterior diaphragmatic defect [2]. Our patient did not benefit from a standard x-ray but from a thoraco-abdomino-pelvic scan performed as part of a check-up. extension for rectal tumor. He showed a voluminous diaphragmatic hernia measuring $115 \times 61 \mathrm{~mm}$ through a right retro-costo-diaphragmatic dehiscence with omental and fatty content, the neck of which measures $24 \mathrm{~mm}$ in diameter. Absence of abnormalities of the cardiac structures.

The indication for surgery in symptomatic subjects is definite. In the event of an accidental discovery in newborns or young children, given the anesthetic risks and the difficulty of performing a minimally invasive procedure, preventive surgery poses a problem of delay $[4,1]$. Our patient was 55 years old, the diagnosis was fortuitous, and she was asymptomatic so no treatment was offered.

The radiographic control after 3 months of the first examination was consistent with the first examination both clinically and radiologically.

\section{CONCLUSION}

La hernie de Morgagni est une entité rare, de découverte le plus souvent fortuite. Néanmoins, cette hernie est souvent asymptomatique ne nécessitant aucun traitement. Le diagnostic positif est évoqué fortuitement au scanner au cours d'un autre bilan et la surveillance peut se faire à la radiographie standard à la fin de limiter l'irradiation aux rayons $\mathrm{X}$.

Declaration of Conflicts of Interest: The authors declare no conflict of interest.

\section{Contributions from the authors}

All authors contributed to data acquisition, data analysis and interpretation, and article writing.

\section{RÉFÉRENCES}

1. Horton, J. D., Hofmann, L. J., \& Herz, S. P. (2008). Présentation et prise en charge des hernies de Morgagni chez l'adulte: revue de 298 cas. Surg Endosc, 22, 1413-1420.

2. Favre, J. P., Hagry, O., \& Cheynel, N. (2002). Traitement chirurgical des hernies diaphragmatiques rares. Encycl Med Chir Editions Scientifiques et Médicinales Elsevier Paris; Techniques chirurgicales-Appareil digestif, 40-247.

3. Cullen, M. L., Klein, M. D., \& Philipart, A. I. (1985). Hernie diaphragmatique congénitale. Surg Clin Amérique du Nord, 65, 1115-1138.

4. Rowe, M. I., \& Uribe, M. L. (1971). Hernie diaphragmatique chez le nouveau-né : considérations relatives aux gaz du sang et au $\mathrm{pH}$. Surg, 70(5), p. 758-761.

5. Daou, R., Serhal, S., Jureidini, F., \& Demian, P. (1992). Hernie rétro-costo-xyphoïdienne de l'adulte: à propos de 3 observations. Chirurgie (Paris), 118(1-2), 59-62.

6. Lev-Chelouche, D., Ravid, A., Michowitz, M., Klausner, J. M., \& Kluger, Y. (1999). Morgagni hernia: unique presentations in elderly patients. Journal of clinical gastroenterology, 28(1), 81-82.

7. Perrotin, J., \& Moreaux, J. (1965). Chirurgie du diaphragme. Paris: Masson.

8. Moreaux, J. (1997). Hernies diaphragmatiques de l'adulte. Rév Prat, 47, 277-281.

9. Ketonen, P., Mattila, S. P., Mattila, T., \& Jarvinen, A. (1975). Traitement chirurgical d'une hernie par le foramen de Morgagni. Acta Chir Scand, 141, 633-636. 